Research Article

\title{
Acoustic Emission and Fractal Precursory Characteristics of Coals with Different Bursting Liabilities in Loading Failure Process
}

\author{
Chao Wang $\mathbb{D}^{1,2}$ Yuefeng Li, ${ }^{1}$ Yong Li, ${ }^{1}$ Jianhui Xu, ${ }^{1}$ and Chengliang Zhang ${ }^{1,2}$ \\ ${ }^{1}$ Faculty of Land Resource Engineering, Kunming University of Science and Technology, Kunming 650093, China \\ ${ }^{2}$ Yunnan Key Laboratory of Sino-German Blue Mining and Utilization of Special Underground Space, Kunming 650093, China \\ Correspondence should be addressed to Chengliang Zhang; zhangchengliang@kust.edu.cn
}

Received 22 April 2021; Accepted 25 June 2021; Published 13 July 2021

Academic Editor: Chao Xu

Copyright (c) 2021 Chao Wang et al. This is an open access article distributed under the Creative Commons Attribution License, which permits unrestricted use, distribution, and reproduction in any medium, provided the original work is properly cited.

\begin{abstract}
Aimed at investigating the differentiation of acoustic emission (AE) signals and fractal precursory characteristics between strong, weak, and no bursting liability coals under uniaxial compression, as well as improving the accuracy of rockburst monitoring and early warning by AE techniques, we experimentally studied the evolution law and differences of AE ring count rate, energy rate, and correlation dimension between different loaded bursting liability coals by the YAW4306 electric mechanical test system and CTA-1 AE monitor. Our experimental results indicated that the AE count and energy of coal samples with different bursting liabilities showed a similar evolution law of "sharp increase-calm-sharp increase" before their main rupture. The active points of AE signals emitted from coal with strong, weak, and no bursting liability appeared at about $85 \sim 90 \%, 75 \sim 78 \%$, and 51 55\% of the peak stress, respectively. The stronger the bursting liability of coal, the shorter the duration of main rupture and postpeak failure stage, and the greater the $\mathrm{AE}$ energy rate in the main rupture. The $\mathrm{AE}$ counts of different coals had obvious fractal characteristics, and the AE correlation dimension values of strong and weak bursting liability coal samples presented the phenomenon of "fluctuating rise to a peak value-sharp drop-continuous decrease," which can be used as a precursory information of coal failure.
\end{abstract}

\section{Introduction}

China is the world's largest coal consumer and has experienced the most serious coal and rock dynamic disasters $[1,2]$, such as coal and gas outburst [3], rockburst [4], and roof fall [5]. Since the first rockburst occurred at the South Stafford coalfield in the United Kingdom in 1738, this catastrophic event has threatened almost all coal mining countries in the world over the past 283 years, including Poland [6], USA [7], Czech [8], France [9], and China [10]. Among these countries, China has had the most serious cases. Traditionally, rockburst is considered as a dynamic phenomenon of sudden and intense release of elastic energy accumulated in coal-rock mass during mining, which is not only harmful and wide-ranging, but may also induce a series of secondary disasters, including abnormal gas gushing and gas explosion [11-17]. For example, on 14 February 2005, a gas explosion induced by rockburst occurred in the Sunjiawan coal mine, located in Fuxin city of Liaoning Province, China, killing 214 workers. As of June 2019, the number of operating rockburst mines in China was 121, distributed in 14 provinces. Among these, in 5 provinces, i.e., Shandong Province, Shaanxi Province, Heilongjiang Province, Gansu Province, and the Inner Mongolia Autonomous Region, the number of operating rockburst mines reached 10, as shown in Figure 1. In addition, the total number of rockburst coal mines is on the rise with the steady increase of underground mining depth.

The prevention and control of rockburst is a global challenge for the underground mining industry. Coal and rock with strong or weak bursting liability are the key factors in the occurrence of the phenomenon. Table 1 lists typical rockburst disasters that occurred in China in the past nearly 5 years, namely, from 2016 to 2020 . The coal seam, roof, and 


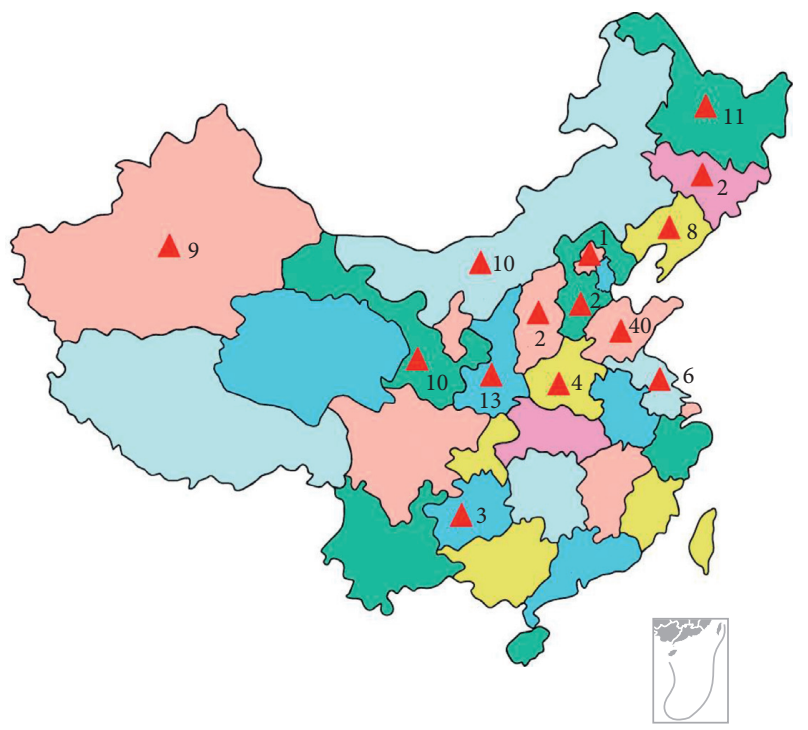

FIGURE 1: Quantity and distribution of rockburst mines being mined in China (up to June 2019) [18].

TABLE 1: Typical rockburst accidents in nearly past 5 years (2016 2020) of China.

\begin{tabular}{lccc}
\hline Date & Accident coal mine & $\begin{array}{c}\text { Accident } \\
\text { fatalities }\end{array}$ & Bursting liability of coal or rock \\
\hline $2016 / 07 / 22$ & Dongbaowei Coal Mine in Heilongjiang & 2 & Weak bursting liability coal and floor, strong bursting liability \\
roof
\end{tabular}

floor of the coal mines where incidents occurred had a certain bursting liability.

The AE signals generated during the loading failure process of coal or rock with bursting liability contain rich information and can reflect the deformation and failure of coal and rock to some extent $[19,20]$. Thus, the measurement and study of AE signals can help us explore the failure mechanism of coal or rock, as well as monitor and forecast coal or rock failure and rockburst [21, 22]. Many researchers have conducted laboratory experiments or field tests from different aspects to investigate the AE characteristics of coal or rock under loading. Wang et al. [23] analyzed the features of AE spectrum in the process of coal fracture and found that the larger the load and the stronger the deformation and the fracture, the higher the frequency zone of the AE signal. Lotidis and Nomikos [24] studied the AE evolution law of hollow plate specimens of two calcitic marbles in the laboratory under uniaxial loading and found that the overall percentage of the signals attributed to tensile AE sources was in the order of $90 \%$, while most of the located shear $\mathrm{AE}$ sources were nucleated after the sidewall's rock failure. He et al. [25] discussed the failure process characteristics of limestone under true triaxial condition. When the limestone sample was under relatively low load, the AE signals showed the characteristics of high frequency and low amplitude. As the load was increased, the AE signals tended to shift further towards a signature of high amplitude. During the process from unloading to failure, the cumulative AE energy release increased rapidly. Zhang et al. [26] established that the $b$ value of AE had no obvious change at the initial stage of loading, but the spatial correlation length $\xi$ presented upward trend during this period, and information entropy $H$ was not sensitive to the damage state of samples during most of the loading process period, while these three parameters showed a significant changing trend before the buckling failure of samples. Pradhan et al. [27] monitored the stressinduced fracture of rock samples by AE and confirmed that the amplitudes and energies of AE events clearly indicated the initiation and propagation of main fractures. Zhang et al. [28] experimentally researched the AE characteristics of rock failure under uniaxial multistage loading. The AE activity of several rock samples was high near the peak strength, the number of $\mathrm{AE}$ events tended to be flat, the $\mathrm{AE}$ event rate decreased, and then the phenomenon of $\mathrm{AE}$ quiet period 
appeared. Moradian et al. [29] discussed the correlating AE sources with damaged zones during the direct shear test of rock joints and concluded that the AE method had a good capability in localizing the failure points and the intensity (energy) failure of asperities. Zhang et al. [30] explored the energy accumulation, dissipation form, and damage evolution process of coal with strong bursting liability under multistage cyclic loading in order to fully identify the failure precursor of coal. The study by Yang [31] indicated that the $\mathrm{AE}$ energy rate and the total energy amount tended to be active and could be used as precursory information for coal damage. As the bursting liability increased, the AE energy tended to be actively lagging. Li et al. [32] discovered that the $\mathrm{AE}$ activity of coal with strong or weak bursting liability had obvious periodicity and was closely associated with the stress change; a large number of high-energy AE signals suddenly appeared near the fracture instability of coal with different bursting liabilities, and the released energy value of coal elevated with the increase of bursting liability. Mu et al. [33] discussed the response characteristics of uniaxial compression mechanics and $\mathrm{AE}$ of coal with different joint angles. The bursting liability of coal samples was stronger with the increase of angle $(\alpha)$ between the loading direction and the joint surface, and the values of AE early warning parameters were different.

Fractal theory is an effective tool for studying nonlinear systems. Since its establishment in the 1970s, many scholars have conducted extensive exploratory studies of the AE fractal of coal and rock under loading [34]. Xie [35] successfully combined the damage mechanics and fractal geometry and created a new research field, namely, rock fractal theory. Hirata et al. [36] studied the fractal dimension of $\mathrm{AE}$ event distribution of intact rock sample and fractured rock. By conducting triaxial compression experiments, Kusunose et al. [37] found that the AE fractal dimension values changed with different granite textures. Fractal signals from noisy measurements were estimated based on wavelet analysis developed by Wornell and Oppenheim [38]. Lei et al. [39] analyzed the spatial distribution and fractal structure of AE focuses of Inada granite under triaxial compression and showed that the fractal dimension values differed from the lithologies. Gao et al. [40] suggested that the reduction of fractal dimension could be a valuable parameter to predict the occurrence of major cracks or failure. Through laboratory loading compression tests of different rocks, Yin et al. [41] proposed a precursor to predict rock failure; that is, the fractal dimension values went down to the minimum near the peak stress. Li et al. [42] conducted uniaxial cyclic loading tests on three types of rocks and pointed out that the $\mathrm{AE}$ event rate, energy rate, and spatial distribution all exhibited fractal characteristics. Carpinteri et al. [43] analyzed the fractal characterization of fracture surfaces in rock and used fractal geometry to characterize the roughness of the cracked concrete surfaces. By studying $\mathrm{AE}$ and fractal characteristics of different damage types of rock under uniaxial compression, Gao et al. [44] revealed that the fractal dimension value would jump up before rock damage. Guo et al. [45] discussed the AE fractal characteristics of coal samples with bursting liability under uniaxial loading and suggested the phenomenon that the AE fractal dimension reached a peak and then a sudden drop, which could be used as a precursor to coal damage.

In the past several decades, many scholars conducted extensive laboratory and field experiment researches on the $\mathrm{AE}$ signals and fractal evolution of coal or rock under loading and achieved remarkable results. However, the present research mainly focuses on a certain kind of coal samples, such as strong bursting liability coals, to analyze the $\mathrm{AE}$ signals and fractal characteristics of $\mathrm{AE}$; there are few reports on the comparative study between three different bursting liability coals. Due to the differences in the degree of anisotropy, porosity, crack development, and failure process of coals with different bursting liabilities, the $\mathrm{AE}$ characteristics during the failure process are also different. Thus, through laboratory loading compression tests of different bursting liability coals, this paper explores the differentiation of AE signals and fractal characteristics between coals with strong, weak, and no bursting liability and investigates the precursory information of coal in the failure process. The results provide a reference for further improving the forecasting accuracy of rockburst by $\mathrm{AE}$ techniques and have certain theoretical and practical significance for ensuring coal mine safety.

\section{Experimental System}

2.1. Experimental Devices. The experimental system is mainly composed of an axial loading system, an AE data acquisition system, and a shielding system. Figures 2 and 3 show its schematic diagram and physical map, respectively. The loading system is a YAW4306 electric mechanical test system with a maximum load of $3000 \mathrm{kN}$ and is suitable for shear test, split tensile test, elastic static modulus test, and flexural strength test. Its test power resolution is better than $15 \mathrm{~N}$, and the relative error rate and test range are $\pm 1 \%$ and $2 \sim 100 \%$, respectively. The $\mathrm{AE}$ data acquisition system comprises a CTA-1 acoustic emission monitor manufactured by Physical Acoustics, which consists mainly of a filter, a preamplifier, an $\mathrm{A} / \mathrm{D}$ converter, and a computer, and can be used for signal acquisition, analog-to-digital signal conversion, data storage, and graphic display. The 8-channel data acquisition system can collect $\mathrm{AE}$ signals in real-time through the AEwinRockTest software, which is convenient for the spectrum analysis of data tested in the experiment.

The resonant frequency of $\mathrm{AE}$ sensor for the experiment was set as $49.8 \mathrm{kHz}$. We fixed the AE sensors symmetrically on the sidewall of coal sample with tape and coated Vaseline between sensor and sample to ensure that the AE signals generated during the deformation and failure process were well received by the sensor. We conducted $\mathrm{AE}$ experiments with coal samples loaded under uniaxial compression at the loading rate of $0.005 \mathrm{~mm} / \mathrm{s}$ using the displacement mode. In this paper, the sampling frequency and threshold of CTA-1 $\mathrm{AE}$ monitor were set as $500 \mathrm{kHz}$ and $45 \mathrm{~dB}$, respectively, and the AE signals and load were collected synchronously in the failure process of coal samples. 


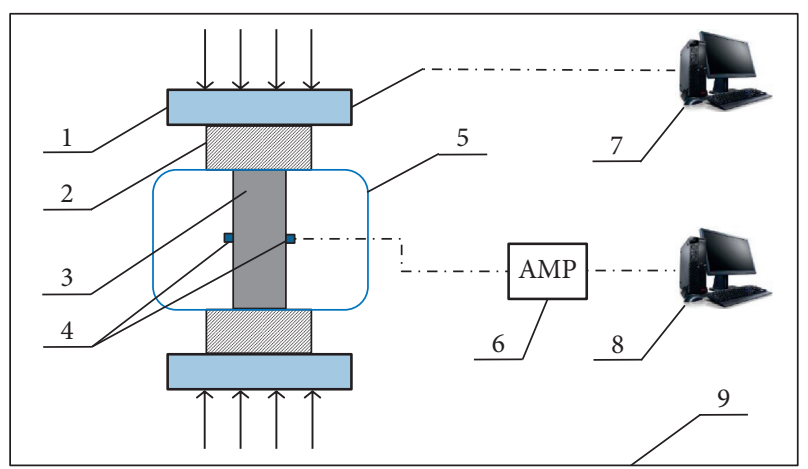

FIgURE 2: Schematic diagram of experimental system. (1) Compression testing machine; (2) insulating gasket; (3) coal sample; (4) AE sensor; (5) shielding system; (6) preamplifier; (7) AE data acquisition system; (8) loading control system; (9) shielding room.

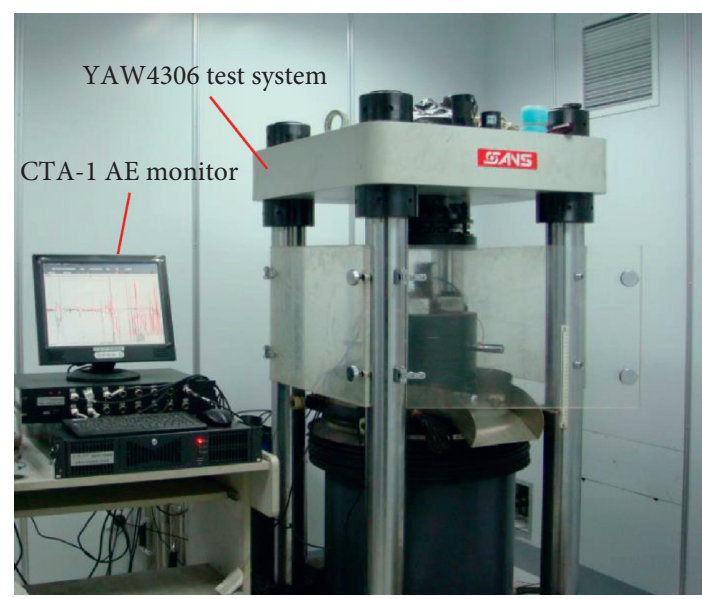

Figure 3: Physical map of the experimental system.

2.2. Coal Sample Preparation and Bursting Liability Test. Experimental coal samples were extracted from strong, weak, and no bursting liability coal seams, respectively. In the hope of maintaining the original state of coal, samples were taken from the same or adjacent large coal blocks and prepared as standard cylindrical coal samples with a diameter of $50 \mathrm{~mm}$ and length of $100 \mathrm{~mm}$ according to the recommendations by the International Society of Rock Mechanics (ISRM). Figure 4 shows the partial experimental coal samples.

In accordance with the National Standard of People's Republic of China entitled "Classification and laboratory test method on bursting liability of coal (GT/T25217.22010)," the classification criteria of coal bursting liability, presented in Table 2, were applied [46]. The coal samples numbered as $Q 1 \sim Q 3, R 1 \sim R 3$, and $W 1 \sim W 3$ were sampled from the Yuejin Coal Mine, Anju Coal Mine, and Qianshuta Coal Mine, respectively. The average values of bursting liability indices, i.e., the duration of dynamic fracture index $(\mathrm{DT})$, elastic strain energy index $\left(W_{\mathrm{ET}}\right)$, bursting energy index $\left(K_{E}\right)$, and uniaxial compressive strength index $\left(R_{C}\right)$, were determined. The evaluation results for samples are illustrated in Table 3.

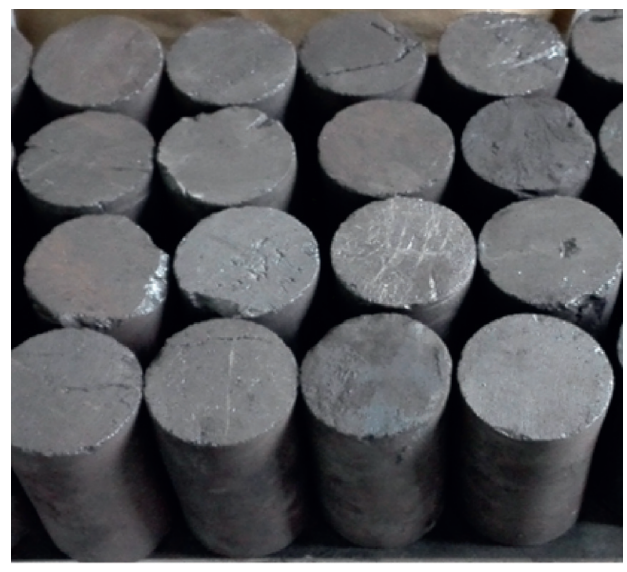

Figure 4: Partially processed coal samples.

\section{Results and Analysis of AE Experiment}

3.1. AE Signal Analysis. We conducted a series of uniaxial compression experiments with different bursting liability coal samples and collected the AE count rates and energy rates. The relationships among $\mathrm{AE}$ count rate, cumulative count, AE energy rate, cumulative energy, and stress with time are depicted in Figures 5-7 .

As seen from the above figures, the $\mathrm{AE}$ signals emitted from loaded coal samples were significantly different between the five stages of the whole deformation and failure process. Generally, the AE count rate and energy rate were proportional to the number and magnitude of cracking events. In the compaction stage, the cracks inside coal sample closed and microcracks slowly developed primarily in a small range, resulting in fewer $\mathrm{AE}$ signals and keeping a calm state; the cumulative counts and energy increased at a slow pace. In the elastic deformation stage, when the microcracks and joints had been completely compacted, the coal sample appeared to partially fracture, and the fluctuating $\mathrm{AE}$ signals slightly increased. In the plastic deformation stage, part of the cracks inside the coal sample continued to be compacted, a large number and density of new cracks and microcracks were produced, and the fluctuating $\mathrm{AE}$ signals increased, indicating the entrance of $\mathrm{AE}$ into the accelerated growth stage. Near the main rupture stage, many cracks had been produced in the coal samples. With the continuous increase of load, all kinds of cracks connected and merged with each other, and a large amount of energy was released. When the strength of coal was insufficient to bear the heavy load, crack propagation and penetration caused macroscopic rupture, and the AE signals increased rapidly to the peak value. In the residual deformation stage, the AE signals greatly reduced. The proportion of each stage in the whole deformation and failure process of coal samples varied with the coal's bursting liability. Specifically, the stronger the bursting liability of coal, the larger the proportion of compaction and elasticity stage that accounted for the overall failure process; the longer the elastic energy accumulation time of coal is, the smaller the proportion of plastic failure stage is and the more suddenly the coal sample was damaged. 
TABLE 2: Classification criteria of coal's bursting liability.

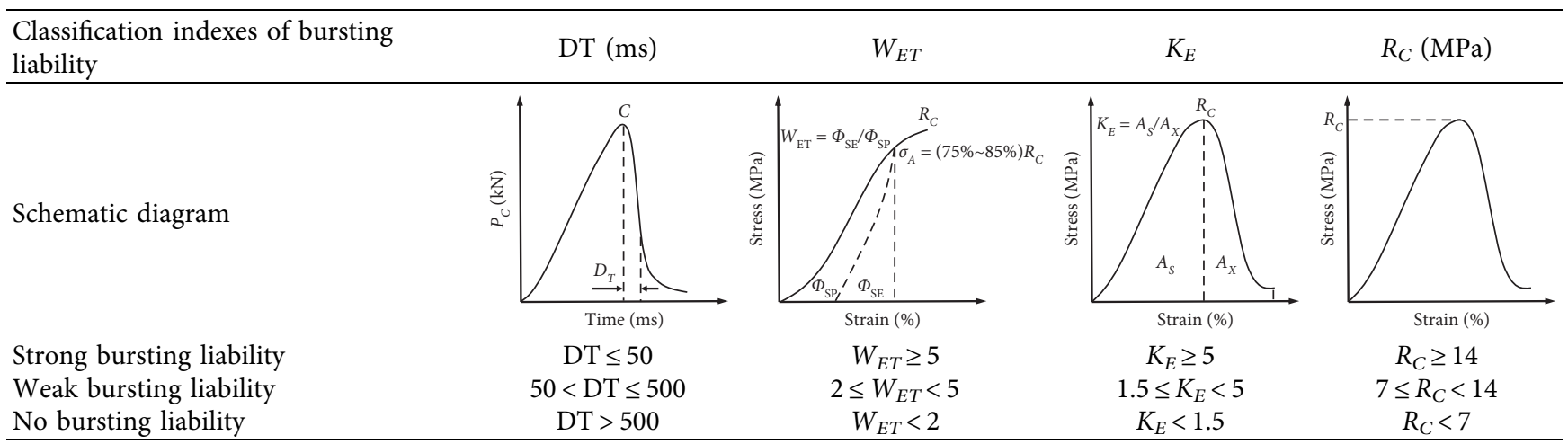

TABLE 3: Bursting liability data of coal samples.

\begin{tabular}{|c|c|c|c|c|c|c|c|c|}
\hline \multirow[t]{2}{*}{ Sample source } & \multirow[t]{2}{*}{ Sample no. } & \multicolumn{2}{|c|}{ Dimensions (mm) } & \multicolumn{4}{|c|}{$\begin{array}{c}\text { Average value of bursting liability } \\
\text { indexes }\end{array}$} & \multirow[t]{2}{*}{ Evaluation result } \\
\hline & & Length & Diameter & DT (ms) & $W_{E T}$ & $K_{E}$ & $R_{C}(\mathrm{MPa})$ & \\
\hline \multirow{4}{*}{ Yuejin Coal Mine } & Q1 & 100.1 & 50.1 & & & & & \\
\hline & Q2 & 100.2 & 49.5 & 72 & 6.18 & 8.34 & 25.7 & Strong bursting liability \\
\hline & Q3 & 99.6 & 49.8 & & & & & \\
\hline & $R 1$ & 100.1 & 50.3 & & & & & \\
\hline \multirow[t]{3}{*}{ Anju Coal Mine } & $R 2$ & 100.4 & 49.3 & 483 & 2.31 & 1.22 & 7.3 & Weak bursting liability \\
\hline & $R 3$ & 99.8 & 50.2 & & & & & \\
\hline & $W 1$ & 100.3 & 50.4 & & & & & \\
\hline \multirow[t]{2}{*}{ Qianshuta Coal Mine } & $W 2$ & 100.3 & 49.6 & 820 & 1.22 & 1.41 & 5.4 & No bursting liability \\
\hline & $W 3$ & 99.4 & 49.5 & & & & & \\
\hline
\end{tabular}

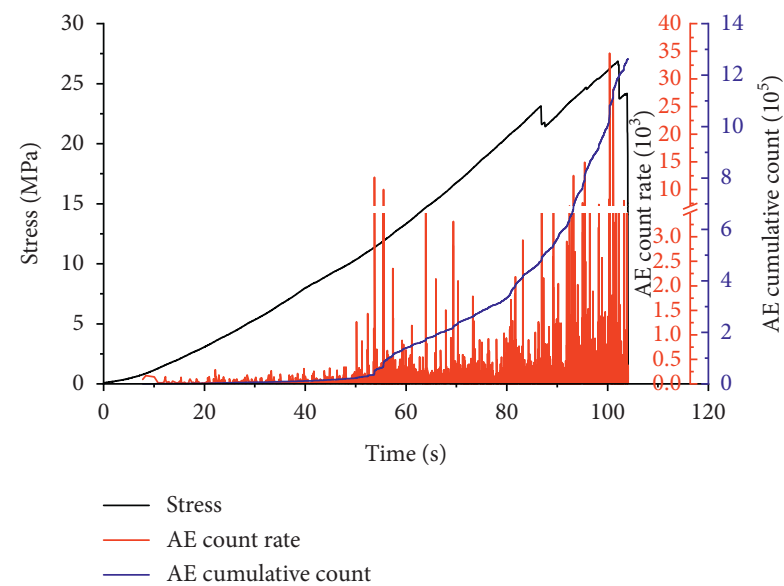

(a)

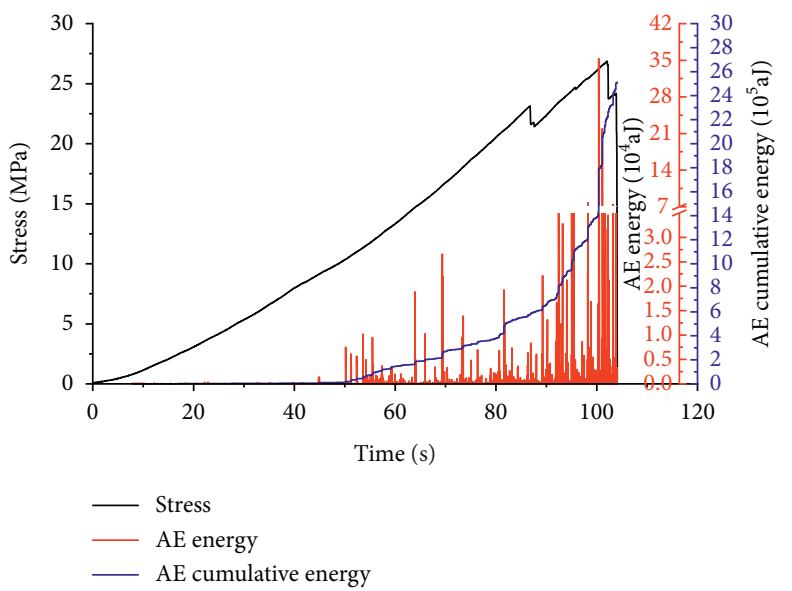

(b)

FIgURE 5: (a) AE count rate and cumulative count. (b) AE energy rate and cumulative energy of strong bursting liability coal.

Furthermore, throughout the whole process of loading failure of coal samples, whenever there was a large fracture inside a coal sample, the AE signals would increase periodically, as shown at about $83 \mathrm{~s}$ in Figure 5(a), at about $79 \mathrm{~s}$, $113 \mathrm{~s}$, and $119 \mathrm{~s}$ in Figure 6(a), and at about $135 \mathrm{~s}$ and $170 \mathrm{~s}$ in Figure 7(a), etc. Moreover, the increase of AE ring count rate was not necessarily continuous but could also exhibit surges. The occurrence of observed large ring count rate is the result of energy release in the process of crack propagation and accumulation, and there is a good corresponding relationship between AE signals and coal sample failure. 
According to Figures 5-7 and the above analysis, the AE characteristics of coal samples with strong, weak, and no bursting liability during the loading failure process are presented in Table 4 . The comparative analysis demonstrated that, before the main rupture of coal samples, the AE signals emitted from coal samples with different bursting liabilities under loading showed a similar evolution law of "sharp increase-calm-sharp increase," but the precursor times of $\mathrm{AE}$ signals and the $\mathrm{AE}$ energy rate at the main rupture time were different. The active points of $\mathrm{AE}$ signals of strong, weak, and no bursting liability coals appeared at about $85 \sim 90 \%, 75 \sim 78 \%$, and $51 \sim 55 \%$ of the peak stress value, respectively, which indicated that the stronger the bursting liability of coal, the more lagging the active point of $\mathrm{AE}$ signals, and the shorter the time for early warning of coal failure, the shorter the duration of main rupture and postpeak failure stage (namely, it dropped from $113 \mathrm{~s}$ to $2 \mathrm{~s}$ ) and the higher the AE energy rate in main rupture. Specifically, the energy rate of strong bursting liability coal was 5.6 times and 1.8 times that of weak and no bursting liability coal, respectively.

3.2. Evolution Analysis of Correlation Dimension. The fractal dimension is a key parameter to describe the characteristics of fractal structures, namely, the complexity of fractal. The disordered development of internal cracks of a loaded coal sample can be measured by the correlation dimension $D$, which can reflect the development and evolution of the internal damage and failure of coal. The calculation method of correlation dimension used in this paper is the $G-P$ algorithm, proposed by P. Grassberger and I. Procaccia in 1983, which takes the AE parameter sequence as the research object. Each AE parameter series corresponding to one set $X_{0}$ with a capacity $n$ can be obtained:

$$
X_{0}=\left\{x_{1}, x_{2}, x_{3}, \cdots, x_{n}\right\}
$$

An $m$-dimensional phase space is constructed according to equation (1). First, $m(m<n)$ numbers are selected from the time series as a vector in the $m$-dimensional space, and the vector is expressed as

$$
X_{1}=\left\{x_{1}, x_{2}, x_{3}, \cdots, x_{m}\right\},
$$

where $m$ is the embedding dimension.

Then, moving one data point to the right forms the second phase space vector $X_{2}$ :

$$
X_{2}=\left\{x_{2}, x_{3}, x_{4}, \cdots, x_{m+1}\right\} \text {. }
$$

According to above method, $m$-dimensional vectors with a capacity of $N(N=n-m+1)$ are constructed, and the $N^{\text {th }}$ vector is

$$
X_{n-m+1}=\left\{x_{n-m+1}, x_{n-m+2}, x_{n-m+3}, \cdots, x_{n}\right\} .
$$

Finally, the reconstructed phase space $X$ is established as follows:

$$
X=\left[\begin{array}{ccccc}
x_{1} & x_{2} & \cdots & x_{n-m} & x_{n-m+1} \\
x_{2} & x_{3} & \cdots & x_{n-m+1} & x_{n-m+2} \\
\cdots & \cdots & \cdots & \cdots & \cdots \\
x_{m-1} & x_{m} & \cdots & x_{n-2} & x_{n-1} \\
x_{m} & x_{m+1} & \cdots & x_{n-1} & x_{n}
\end{array}\right] .
$$

The corresponding correlation function is defined as

$$
C(r)=\frac{1}{N^{2}} \sum_{i=1}^{N} \sum_{j=1}^{N} H\left(r-\left|X_{i}-X_{j}\right|\right),
$$

where $r$ represents the measurement scale, $N$ represents the number of time series data, and $H(x)$ is the Heaviside step function, which can be expressed as

$$
H(x)= \begin{cases}1, & x \geq 0, \\ 0, & x<0 .\end{cases}
$$

For a given $r$, there is a corresponding correlation function $C(r)$ according to equation (6). Subsequently, the points $(\ln C(r), \ln r)$ are plotted in double logarithmic coordinates and fitted. Different $r$ values are selected one by one, and then multiple sets of data are drawn in the coordinate system. Then, the unary linear regression of $\ln C(r)$ and $\ln r$ is carried out, and the value of correlation dimension $D$ can be defined by the slope of straight line in the $\ln C(r)-\ln r$ curve as follows:

$$
D=\left|\lim _{r \longrightarrow 0} \frac{\ln C(r)}{\ln r}\right|
$$

Taking the case of a weak bursting liability coal, the peak stress ratio was divided into 20 groups from $0 \sim 5 \%$ to $95 \sim 100 \%$, and the $D$ value of each group of stress corresponding to AE count was calculated by using MATLAB, as presented in Table 5. The fitting correlation coefficient $r$ of each group was greater than 0.85 , and that of 10 groups was no less than 0.9 , indicating that the $\mathrm{AE}$ count rate of loaded weak bursting liability coal has obvious fractal characteristics during sample failure. Simultaneously, the same conclusion was obtained from coals with strong and no bursting liability.

When the damage of the coal body reaches a certain extent, the fracture will lead to disaster, and the fractal dimension of AE signals can accurately reflect the precursory information. Figure 8 shows the AE correlation dimension evolution of loaded coal samples with strong, weak, and no bursting liability before the main rupture. It can be observed that the correlation dimension $D$ values differ significantly at different stress levels. In detail, when the load level is low, the corresponding $D$ value of AE time series is also low, which reflects the law of coal deformation and failure approaching the initial equilibrium. With the increase of load, the $D$ value increases to the maximum, indicating the disorder of coal deformation and failure.

Due to many differences between coals with strong, weak, and no bursting liability, including physical and mechanical properties, internal crack propagation mode, deformation and fracturing process, energy accumulation 


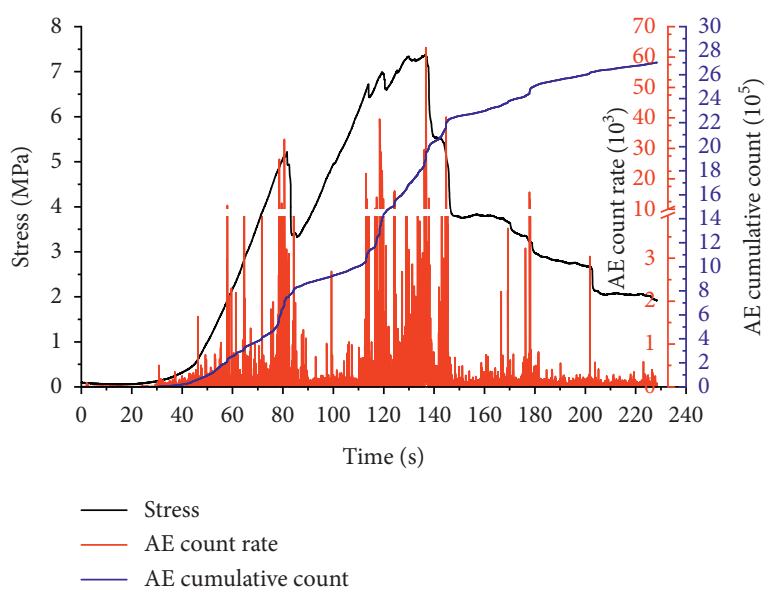

(a)

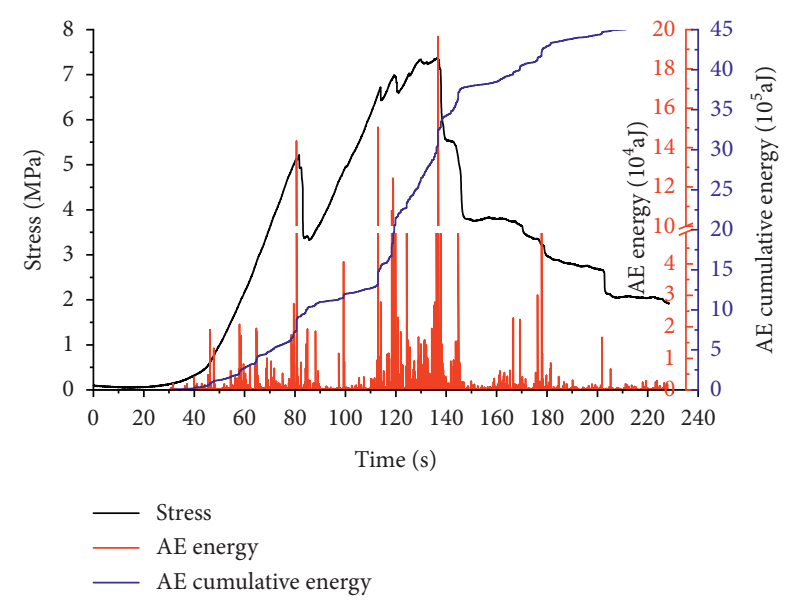

(b)

Figure 6: (a) AE count rate and cumulative count. (b) AE energy rate and cumulative energy of weak bursting liability coal.

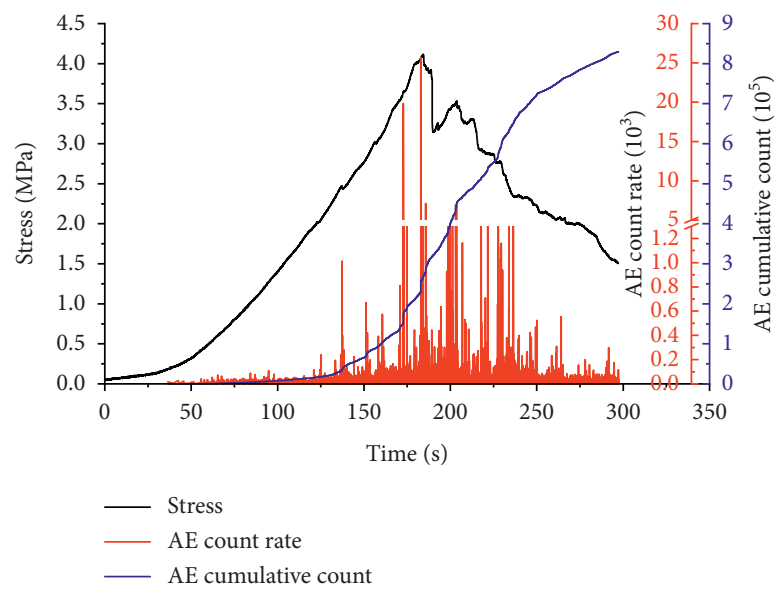

(a)

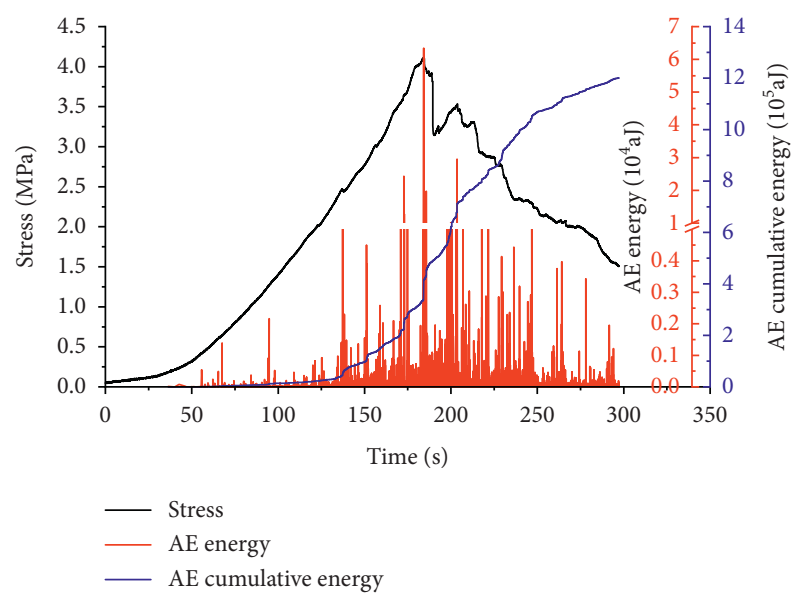

(b)

FIgURE 7: (a) AE count rate and cumulative count. (b) AE energy rate and cumulative energy of no bursting liability coal.

TABLE 4: AE characteristics of different coal samples.

\begin{tabular}{lcccc}
\hline $\begin{array}{l}\text { Bursting liability type } \\
\text { of coal }\end{array}$ & $\begin{array}{c}\text { Peak stress value } \\
(\mathrm{MPa})\end{array}$ & AE precursor position & $\begin{array}{c}\text { AE energy rate in main } \\
\text { rupture point }\end{array}$ & $\begin{array}{c}\text { Duration of postpeak failure } \\
\text { stage }(\mathrm{s})\end{array}$ \\
\hline Strong & 26.9 & $\begin{array}{c}\text { During } 85 \sim 90 \% \text { stress level to } \\
\text { peak strength }\end{array}$ & 353157 & 2 \\
Weak & 7.4 & $\begin{array}{c}\text { During } 75 \sim 78 \% \text { stress level to } \\
\text { peak strength }\end{array}$ & 196605 & 92 \\
No & 4.1 & $\begin{array}{c}\text { During } 51 \sim 55 \% \text { stress level to } \\
\text { peak strength }\end{array}$ & 63456 & 113 \\
\hline
\end{tabular}

and release mode, and other factors, the evolution law of $\mathrm{AE}$ correlation dimension will be also different. However, the $D$ values of strong and weak bursting liability coal samples showed a similar variation trend, i.e., fluctuating rise to a peak value-sharp drop-continuous decrease. That is, in the stable initial loading stage, the $D$ value firstly increased slowly and fluctuated within a smaller range, all cracks of different kinds in the coal sample closed, and the damage gradually began to develop. Then, the $D$ value gradually increased and reached the maximum value when the stress level exceeded $50 \%$ of the peak stress. Subsequently, when it reached $80 \sim 90 \%$ of the peak value, the $D$ value dropped sharply. With the continuous rise of the damage level of coal sample, the $D$ value continued to decrease to the minimum 
TABLE 5: AE correlation dimension of weak bursting liability coal in different failure stages.

\begin{tabular}{lcc}
\hline Peak stress ratio (\%) & Fitting correlation coefficient $r$ & Correlation dimension value $D$ \\
\hline $0 \sim 5$ & 0.85 & 0.80 \\
$5 \sim 10$ & 0.89 & 0.14 \\
$10 \sim 15$ & 0.93 & 0.71 \\
$15 \sim 20$ & 0.88 & 1.16 \\
$20 \sim 25$ & 0.90 & 0.52 \\
$25 \sim 30$ & 0.87 & 0.06 \\
$30 \sim 35$ & 0.88 & 0.14 \\
$35 \sim 40$ & 0.93 & 0.10 \\
$40 \sim 45$ & 0.95 & 0.15 \\
$45 \sim 50$ & 0.95 & 0.60 \\
$50 \sim 55$ & 0.88 & 0.04 \\
$55 \sim 60$ & 0.91 & 0.21 \\
$60 \sim 65$ & 0.87 & 0.53 \\
$65 \sim 70$ & 0.89 & 0.04 \\
$70 \sim 75$ & 0.88 & 0.46 \\
$75 \sim 80$ & 0.94 & 0.44 \\
$80 \sim 85$ & 0.96 & 2.11 \\
$85 \sim 90$ & 0.92 & 0.50 \\
$90 \sim 95$ & 0.97 & 0.03 \\
$95 \sim 100$ & 0.88 & 0.03 \\
\hline
\end{tabular}

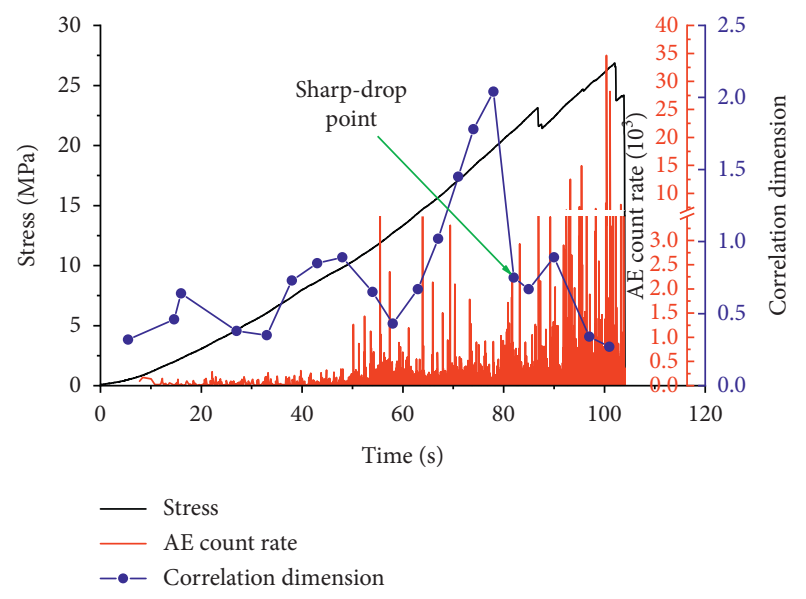

(a)

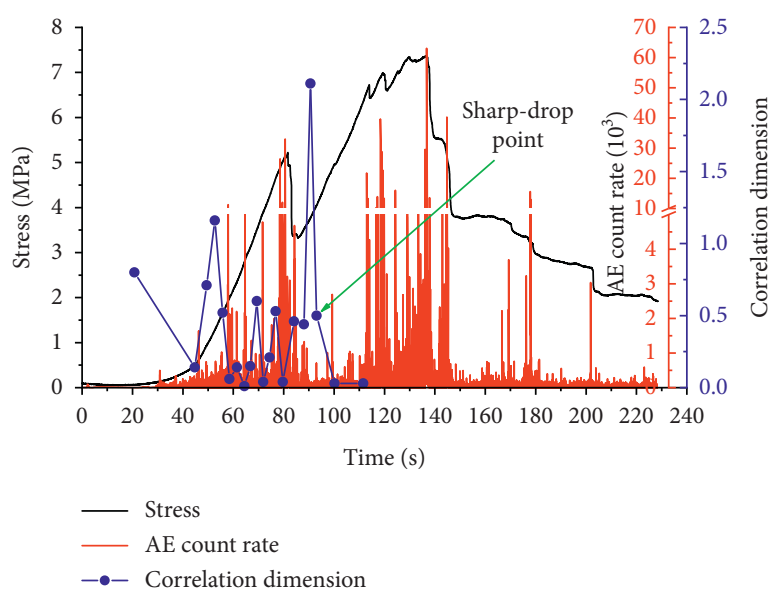

(b)

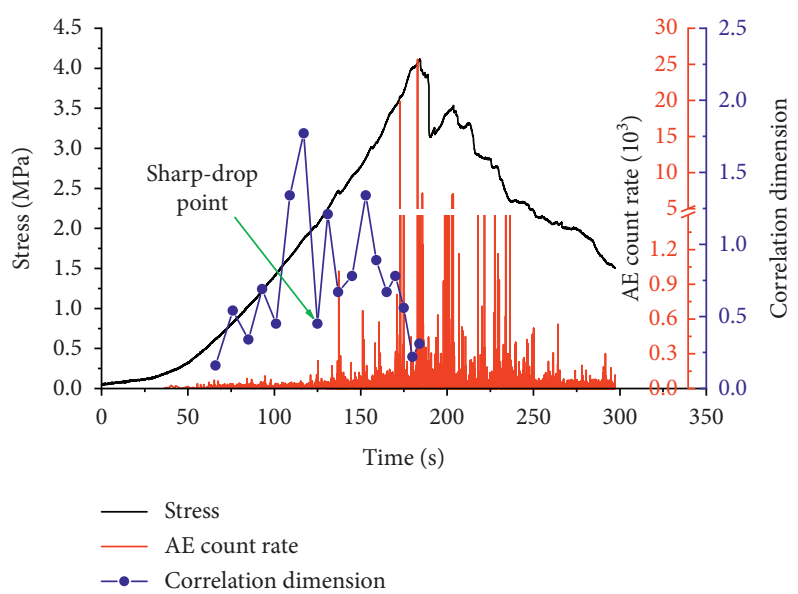

(c)

FIGURE 8: AE correlation dimension evolution of coals with different bursting liabilities in failure process. (a) Strong bursting liability coal. (b) Weak bursting liability coal. (c) No bursting liability coal. 
until the coal sample completely lost its bearing capacity. This variation trend could be used as a precursory information of coal failure. However, the coal with no bursting liability presented a different phenomenon of fluctuating rise to a peak value and then sudden drop to a smaller value, fluctuation to a local peak value several times, and finally continuous decrease, which was significantly different from the process for strong and weak bursting liability coal.

The correlation dimension value $D$ of $\mathrm{AE}$ time series reflected the development degree of microdefects inside the samples. At a low stress level, a large amount of microdamage occurred in coal samples, which were different in size, disorderly, and randomly distributed. As a measure of disorder, the fluctuating increase of $D$ value could well reflect the statistical evolution law of this microdamage, which meant that the crack propagation in coal samples developed gradually from disorder to order. The AE correlation dimension of strong and weak bursting liability coal samples decreased abruptly and continuously declined to the lowest value before sample failure, indicating that the internal microfractures of coal samples gradually merged into a large fracture, and the samples were about to shatter. This research finding has important significance for guiding the prevention of potential rockburst disasters.

\section{Conclusions}

(1) The AE response law of loaded coal is of great significance for early warning signs of rockburst. Our experimental study results indicate that the stronger the bursting liability of coal, the larger the proportion of compaction and elasticity stage accounting for the overall failure process, the longer the elastic energy accumulation time of coal, the smaller the proportion of plastic failure stage, and the more sudden the coal damage.

(2) Prior to the main rupture of coal samples, the AE signals emitted from coal samples with different bursting liabilities under loading showed a similar evolution law of "sharp increase-calm-sharp increase." The active points of AE signals of strong, weak, and no bursting liability coal appeared at about $85 \sim 90 \%, 75 \sim 78 \%$, and $51 \sim 55 \%$ of the peak stress, respectively. The stronger the bursting liability of coal, the shorter the duration of main rupture and postpeak failure stage, and the greater the AE energy rate for the main rupture.

(3) The AE correlation dimensions of strong and weak bursting liability coal samples showed a similar variation trend of "fluctuating rise to a peak valuesharp drop-continuous decrease," which can be used as a precursory information of coal failure.

(4) With the increase of mining depth, coal seam occurrence conditions will become more and more complicated, and a single parameter can no longer meet the requirements of rockburst early warning. It is therefore necessary to build a comprehensive monitoring system by combining the microseismic method, the drilling cutting method, the mining stress monitoring method, and the electromagnetic radiation method to integrate multiple information sources of early warning for the improvement of forecasting accuracy.

\section{Data Availability}

The data used to support the findings of this study are included within the article.

\section{Conflicts of Interest}

The authors declare that they have no conflicts of interest.

\section{Acknowledgments}

This work was supported by the Science and Research Fund from the Educational Department of Yunnan Province (2021J0060), the National Natural Science Foundation of China (51934003 and 51864023), the Yunnan Innovation Team (202105AE160023), the Program for Innovative Research Team (in Science and Technology) in University of Yunnan Province, and the Analysis and Testing Foundation of Kunming University of Science and Technology (2017T20130130).

\section{References}

[1] K. Wang and F. Du, "Coal-gas compound dynamic disasters in China: a review," Process Safety and Environmental Protection, vol. 133, pp. 1-17, 2020.

[2] C. Xu, G. Yang, K. Wang, and Q. Fu, "Uneven stress and permeability variation of mining-disturbed coal seam for targeted CBM drainage: a case study in Baode coal mine, eastern Ordos Basin, China," Fuel, vol. 289, Article ID 119911, 2021.

[3] X. Li, Z. Cao, and Y. Xu, "Characteristics and trends of coal mine safety development," Energy Sources, Part A: Recovery, Utilization, and Environmental Effects, vol. 2020, pp. 1-19, 2020.

[4] D. Song, E. Wang, X. He et al., "Use of electromagnetic radiation from fractures for mining-induced stress field assessment," Journal of Geophysics and Engineering, vol. 15, no. 4, pp. 1093-1103, 2018.

[5] C. Xu, Q. Fu, X. Cui, K. Wang, Y. Zhao, and Y. Cai, “Apparent-depth effects of the dynamic failure of thick hard rock strata on the underlying coal mass during underground mining," Rock Mechanics and Rock Engineering, vol. 52, no. 5, pp. 1565-1576, 2019.

[6] M. Bukowska, "The rockbursts in the upper silesian coal basin in Poland," Journal of Mining Science, vol. 48, no. 3, pp. 445-456, 2012.

[7] C. Mark and M. Gauna, "Evaluating the risk of coal bursts in underground coal mines," International Journal of Mining Science and Technology, vol. 26, no. 1, pp. 47-52, 2016.

[8] J. Ptáček, "Rockburst in ostrava-karvina coalfield," Procedia Engineering, vol. 191, pp. 1144-1151, 2017.

[9] L. Driad-Lebeau, F. Lahaie, M. Al Heib, J. P. Josien, P. Bigarré, and J. F. Noirel, "Seismic and geotechnical investigations following a rockburst in a complex French mining district," International Journal of Coal Geology, vol. 64, no. 1-2, pp. 66-78, 2005. 
[10] T.-b. Zhao, M.-1. Xing, W.-y. Guo, C.-w. Wang, and B. Wang, "Anchoring effect and energy-absorbing support mechanism of large deformation bolt," Journal of Central South University, vol. 28, no. 2, pp. 572-581, 2021.

[11] A. Kidybinski, "Bursting liability indices of coal," International Journal of Rock Mechanics and Mining Science \& Geomechanics Abstracts, vol. 18, no. 6, pp. 295-304, 1981.

[12] P. Horyl and R. Šňupárek, "Reinforcing measures of steel roadway support in rockburst prone areas/Wzmacnianie stalowych obudów chodnikowych w obszarach zagrożonych tąpnięciami," Archives of Mining Sciences, vol. 57, no. 1, pp. 193-208, 2012.

[13] F. Q. Gong, Y. L. Wang, Z. G. Wang, J. F. Pan, and S. Luo, “A new criterion of coal burst proneness based on the residual elastic energy index," International Journal of Mining Science and Technology, vol. 11, 2021.

[14] X. L. Li, S. J. Chen, Z. H. Li, and E. Y. Wang, "Rockburst mechanism in coal rock with structural surface and the microseismic (MS) and electromagnetic radiation (EMR) response," Engineering Failure Analysis, vol. 124, no. 6, Article ID 105396, 2021.

[15] J. Zuo, J. Wang, and Y. Jiang, "Macro/meso failure behavior of surrounding rock in deep roadway and its control technology," International Journal of Coal Science \& Technology, vol. 6, no. 3, pp. 301-319, 2019.

[16] F. Du, K. Wang, X. Zhang, C. Xin, L. Shu, and G. Wang, "Experimental study of coal-gas outburst: insights from coalrock structure, gas pressure and adsorptivity," Natural Resources Research, vol. 29, no. 4, pp. 2481-2493, 2020.

[17] Z. B. Zhang, E. Y. Wang, X. N. Liu et al., "Anisotropic characteristics of ultrasonic transmission velocities and stress inversion during uniaxial compression process," Journal of Applied Geophysics, vol. 186, Article ID 104274, 2021.

[18] Q. X. Qi, Y.Z. Li, S. K. Zhao et al., "Seventy years development of coal mine rockburst in China: establishment and consideration of theory and technology system," Coal Science and Technology, vol. 47, no. 9, pp. 1-40, 2019.

[19] F. Du, K. Wang, G. Wang, Y. Jiang, C. Xin, and X. Zhang, "Investigation of the acoustic emission characteristics during deformation and failure of gas-bearing coal-rock combined bodies," Journal of Loss Prevention in the Process Industries, vol. 55, pp. 253-266, 2018.

[20] S. He, D. Song, Z. Li et al., "Precursor of spatio-temporal evolution law of MS and AE activities for rock burst warning in steeply inclined and extremely thick coal seams under caving mining conditions," Rock Mechanics and Rock Engineering, vol. 52, no. 7, pp. 2415-2435, 2019.

[21] L. Dou, K. Yang, and X. Chi, "Fracture behavior and acoustic emission characteristics of sandstone samples with inclined precracks," International Journal of Coal Science \& Technology, vol. 8, no. 1, pp. 77-87, 2021.

[22] P. K. Kaiser and M. Cai, "Design of rock support system under rockburst condition," Journal of Rock Mechanics and Geotechnical Engineering, vol. 4, no. 3, pp. 215-227, 2012.

[23] E. Y. Wang, X. Q. He, Z. T. Liu, and Z. H. Li, "Study on frequency spectrum characteristics of acoustic emission in coal or rock deformation and fracture," Journal of China Coal Society, vol. 29, no. 3, pp. 289-292, 2004.

[24] M. A. Lotidis and P. P. Nomikos, "Acoustic emission location analysis and microcracks' nature determination of uniaxially compressed calcitic marble hollow plates," Geomechanics and Geophysics for Geo-Energy and Geo-Resources, vol. 7, no. 2, p. 11, 2021.
[25] M. C. He, J. L. Miao, and J. L. Feng, "Rock burst process of limestone and its acoustic emission characteristics under truetriaxial unloading conditions," International Journal of Rock Mechanics and Mining Sciences, vol. 47, no. 2, pp. 286-298, 2010.

[26] Z. B. Zhang, X. N. Liu, Y. H. Zhang, X. Y. Qin, and K. Majid, "Comparative study on fracture characteristics of coal and rock samples based on acoustic emission technology," Theoretical and Applied Fracture Mechanics, vol. 111, Article ID 102851, 2021.

[27] S. Pradhan, A. M. Stroisz, E. Fjær, J. F. Stenebråten, H. K. Lund, and E. F. Sønstebø, "Stress-induced fracturing of reservoir rocks: acoustic monitoring and $\mu \mathrm{CT}$ image analysis," Rock Mechanics and Rock Engineering, vol. 48, no. 6, pp. 2529-2540, 2015.

[28] R. Zhang, H. P. Xie, J. F. Liu, J. W. Deng, and Q. Peng, "Experimental study on acoustic emission characteristics of rock failure under uniaxial multilevel loadings," Chinese Journal of Rock Mechanics and Engineering, vol. 25, no. 12, pp. 2584-2588, 2006.

[29] Z. A. Moradian, G. Ballivy, and P. Rivard, "Correlating acoustic emission sources with damaged zones during direct shear test of rock joints," Canadian Geotechnical Journal, vol. 49, no. 6, pp. 710-718, 2012.

[30] G. H. Zhang, Z. .G. Deng, J. J. Jiang et al., "Acoustic emission characteristics of coal with strong impact proneness under different loading modes," Journal of Mining \& Safety Engineering, vol. 37, no. 5, pp. 977-982, 2020.

[31] L. Yang, "Acoustic emission energy characteristics and timespace evolution law of coal with different rockburst tendency," Journal of Mining \& Safety Engineering, vol. 37, no. 3, pp. 525-532, 2020.

[32] H. Y. Li, Z. X. Sun, Q. X. Qi, F. M. Li, and S. K. Zhao, "Deformation rules and acoustic emission characteristics of coal with different outburst proneness," Journal of Liaoning Technical University, vol. 36, no. 12, pp. 1251-1256, 2017.

[33] H. W. Mu, X. Q. He, D. Z. Song et al., "Response characteristics and influence mechanism of uniaxial compression mechanics and AE of coal with different joint angles," Journal of China Coal Society, vol. 45, no. 5, pp. 1726-1732, 2020.

[34] B. Mandelbrot, Fractals: Forms, Chance and Dimension, W. H. Freeman, New York, NY, USA, 1977.

[35] H. P. Xie, Introduction to Fractal Rock Mechanics, Science Press, Beijing, China, 1996.

[36] T. Hirata, T. Satoh, and K. Ito, "Fractal structure of spatial distribution of microfracturing in rock," International Journal of Rock Mechanics and Mining Science \& Geomechanics Abstracts, vol. 25, no. 1, pp. 369-374, 1988.

[37] K. Kusunose, X. Lei, O. Nishizawa, and T. Satoh, "Effect of grain size on fractal structure of acoustic emission hypocenter distribution in granitic rock," Physics of the Earth and Planetary Interiors, vol. 67, no. 1, pp. 194-199, 1991.

[38] G. W. Wornell and A. V. Oppenheim, "Estimation of fractal signals from noisy measurements using wavelets," IEEE Transactions on Signal Processing, vol. 40, no. 3, pp. 611-623, 2002.

[39] X. L. Lei, J. Ma, K. Kusunose, O. Nishizawa, and T. Satoh, "Spatial distribution and fractal structure of AE focuses of Inada granite under triaxial compression," Seismology and Geology, vol. 13, no. 2, pp. 97-114, 1991.

[40] F. Gao, J. J. Li, X. Y. Li, and J. Chen, "Fractal analysis of the characteristics of acoustic emission of rock," Journal of Wuhan University of Technology, vol. 27, no. 7, pp. 67-69, 2005. 
[41] X. G. Yin, S. L. Li, H. Y. Tang, and J. L. Pei, "Study on quiet period and its fractal characteristics of rock failure acoustic emission," Chinese Journal of Rock Mechanics and Engineering, vol. 28, no. S2, pp. 3383-3390, 2009.

[42] S. L. Li, C. Y. Lin, J. X. Mao, Y. R. Huang, and J. Y. Hu, "Experimental study on fractal dimension characteristics of acoustic emission of rock under multilevel uniaxial cyclic loading," Engineering Mechanics, vol. 32, no. 9, pp. 92-99, 2015.

[43] A. Carpinteri, G. Lacidogna, and G. Niccolini, "Critical behaviour in concrete structures and damage localization by acoustic emission," Fracture of Materials: Moving Forwards, vol. 312, pp. 305-310, 2006.

[44] B. B. Gao, H. G. Li, and H. M. Li, "Study on acoustic emission and fractal characteristics of different damage types of rock," Chinese Journal of Underground Space and Engineering, vol. 11, no. 2, pp. 358-363, 2015.

[45] H. F. Guo, D. Z. Song, X. Q. He, Q. Lou, and L. M. Qiu, "Fractal characteristics of acoustic emission in different damage degrees of impact coal," Coal Science and Technology, vol. 48, pp. 1-9, 2020.

[46] W.-Y. Guo, T.-B. Zhao, Y.-L. Tan, F.-H. Yu, S.-C. Hu, and F.-Q. Yang, "Progressive mitigation method of rock bursts under complicated geological conditions," International Journal of Rock Mechanics and Mining Sciences, vol. 96, pp. 11-22, 2017. 